\title{
Long-term clinical outcomes of repeat hysteroscopic endometrial ablation after failed hysteroscopic endometrial ablation
}

\author{
Grace W. Yeung ${ }^{1}$ - George A. Vilos ${ }^{1,4}$ - Angelos G. Vilos ${ }^{1}$ - Ayman Oraif ${ }^{1,2}$ • \\ Hanin Abduljabar ${ }^{1}$ - Basim Abu-Rafea ${ }^{3}$
}

Received: 11 April 2015 / Accepted: 9 July 2015 /Published online: 21 July 2015

(C) Springer-Verlag Berlin Heidelberg 2015

\begin{abstract}
The study aims to describe patient characteristics, uterine cavity shape and histopathology, complications, and long-term clinical outcomes of women who failed hysteroscopic rollerball or loop endometrial ablation (HEA) and subsequently consented to repeat hysteroscopic endometrial ablation (RHEA), and is a retrospective cohort study (Canadian Task Force classification II-2). The study was conducted in the university-affiliated teaching hospital. Patients included women who failed primary hysteroscopic endometrial ablation (PHEA, $n=183$ ) and subsequently underwent RHEA by the senior author (GAV) from 1993 through 2007 with a minimum follow-up of 5 years. RHEA was performed under general anesthesia using $26 \mathrm{~F}(\sim 9 \mathrm{~mm})$ resectoscope, monopolar loop electrode in 136 (74.3\%), 3-5 mm rollerball in $41(22.4 \%)$ or combination in $6(3.3 \%)$ women. Patient characteristics, uterine cavity, and clinical outcomes of women who failed PHEA and subsequently consented to RHEA were evaluated by retrospective chart review and patient follow-up including office visits and/or telephone interview. The corresponding median age (range) for PHEA and RHEA was 40 (26-70) and 43 (29-76) years. Indications for PHEA included abnormal uterine bleeding (AUB, $52.7 \%$ ), AUB and dysmenorrhea (25.8\%), dysmenorrhea (18.8\%), and
\end{abstract}

George A. Vilos

george.vilos@lhsc.on.ca

1 Division of Reproductive Endocrinology and Infertility, Department of Obstetrics and Gynecology, Western University, London, Ontario, Canada

2 King Abdul Aziz University, Jeddah, Saudi Arabia

3 Dalhousie University, Halifax, Nova Scotia, Canada

4 The Fertility Clinic, Room E-3620A, London Health Science Centre, 800 Commissioners Road East, London, ON N6A 4G5, Canada others $(2.7 \%)$. Indications for RHEA included persistent AUB (53\%), AUB and uterine/pelvic pain (26.2\%), uterine/pelvic pain only (19.1\%), postmenopausal bleeding $(1.1 \%)$, and thickened endometrium $(0.5 \%)$. Complications of RHEA ( $n=7,3.8 \%$ ) included false passage (3), uterine perforation (2), and bleeding (2). One patient with excessive bleeding required immediate hysterectomy. At a median follow-up of 9 years (5-19), $69 \%$ of women avoided hysterectomy. Repeat hysteroscopic endometrial ablation is a feasible, safe, and long-term effective alternative to hysterectomy for abnormal uterine bleeding from benign causes when performed by experienced surgeons.

Keywords Abnormal uterine bleeding $\cdot$ Heavy menstrual bleeding $\cdot$ Menorrhagia $\cdot$ Hysteroscopic endometrial ablation . Repeat endometrial ablation

\section{Introduction}

First-generation endometrial ablation techniques performed by hysteroscopic endometrial ablation (HEA) were introduced in the 1980s as an alternative to hysterectomy to treat women with abnormal uterine bleeding (AUB) from benign causes. These included endometrial laser ablation and radiofrequency rollerball/bar or transcervical resection of the endometrium (TCRE) $[1,2]$. Second-generation endometrial ablation technologies, also referred to as global endometrial ablation (GEA) or nonhysteroscopic endometrial ablation, were introduced in the 1990s as "automated," easier, and safer alternatives to hysteroscopic endometrial ablation requiring less skill and could be performed in the office [3, 4].

Following endometrial ablation by any technique and technology, including hysteroscopic endometrial ablation (HEA), long-term outcomes (within 10 years) indicate that 15 to $30 \%$ 
of women require additional surgery such as hysterectomy for persistent AUB, uterine/pelvic pain, or both [5-7]. The subsequent $30 \%$ hysterectomy rate after endometrial ablation together with a high satisfaction rate of women who chose hysterectomy as primary treatment of their AUB [7] has raised some serious issues, questions, and concerns regarding the cost-effectiveness, ongoing utilization, and indeed the future of both hysteroscopic and nonhysteroscopic endometrial ablation for the treatment of AUB.

Consequently, many gynecologists resort to hysterectomy for both as primary treatment of AUB and as the next logical step in women who fail primary endometrial ablation. However, in spite of major technological advances in minimally invasive gynecological surgery, hysterectomy remains a major surgical procedure associated with significant morbidity, mortality, and health care costs and resources [7-11].

To minimize the post-ablation hysterectomy rate, a few gynecological surgeons have reported their experience with repeat hysteroscopic endometrial ablation (RHEA) using the resectoscope with [12] or without concomitant utilization of ultrasonic guidance [13-16]. Based on these reports, RHEA appears to be more challenging to perform and may be associated with a higher complication rate [16].

For the above reasons, in our center, we have developed a relatively easy and safe technique and we routinely offer RHEA as an alternative to hysterectomy when primary HEA [17] and non-HEA [18] fail and patients continue to complain of persistent AUB, uterine/pelvic pain, or both.

In the present study, we describe our technique and experience, as well as patient characteristics, indications, and long-term outcomes in women who failed hysteroscopic rollerball or loop endometrial ablation and subsequently consented to RHEA.

\section{Materials and methods}

From 1990 through December of 2007, the senior author (GAV) performed 3768 primary HEA using 3-5-mm rollerball electrodes, $8-\mathrm{mm}$ cutting loop electrodes, or a combination of the two to treat women with AUB. In addition, 183 women who had failed primary HEA underwent RHEA by the same surgeon from January 1991 through December 2007. We are aware that some of our patients who failed primary HEA received various treatments, including repeat ablation and/or hysterectomy, by other gynecologists in the area. Therefore, 183 of 3768 cases represent a minimal rate of approximately $5 \%$ repeat ablations among our initial population.

All women who presented with persistent AUB and/or uterine/pelvic pain after primary HEA had complete assessment including pelvic examination and imaging using abdominal and transvaginal ultrasound and/or MRI when indicated.
Endometrial biopsy was attempted in all women with uterine bleeding but, in the majority of cases, we were unable to access the uterine cavity or obtain an adequate/satisfactory sample in the clinic. For this reason, women with postmenopausal bleeding were also included if the endometrial cavity and endometrium could not be assessed in the office. Consequently, we performed endometrial resection in the majority of cases or D\&C and we always obtained an endometrial sample in the operating room during RHEA.

Patients were offered several treatment options including medical therapy in the presence of adequate and normal endometrial histopathology especially if they were nearing menopause, RHEA, or hysterectomy. When RHEA was chosen, patients were counseled appropriately and informed consent was obtained. None of the patients undergoing RHEA was pretreated to thin the endometrium.

After general anesthesia, with the patient in appropriate stirrups and horizontal dorsolithotomy position, a bimanual pelvic examination was performed to assess the size, shape, mobility, and, most importantly, the position of the uterus. None of the RHEA was performed under ultrasonic or laparoscopic guidance although $30(17 \%)$ women underwent concomitant laparoscopy for a variety of additional indications including pelvic pain and/or pelvic mass.

\section{Technique of repeat hysteroscopic endometrial ablation} Following bimanual pelvic examination, the anterior lip of the cervix was grasped with a double-toothed tenaculum and the cervical canal was gradually dilated up to the level of the internal os (approximately $4 \mathrm{~cm}$ ) using Hagar dilators. Occasionally, a single-toothed tenaculum was applied to the posterior lip of the cervix to redistribute the tension between the anterior and posterior lip of the cervix to minimize the risk of cervical tears and maintain the cervical canal straight. If resistance was encountered with any of the dilators, a 5-mm hysteroscope was used to visualize the cervical canal and internal os. Bearing in mind the length and direction of the cervical canal and the position of the uterus, the cervical canal was subsequently dilated to $10 \mathrm{~mm}$.

The resectoscope was introduced, and the endocervical canal was superficially resected to facilitate inflow and outflow of the distending/irrigant solution and visualize better the utero-isthmic junction and any residual uterine cavity. Up to the year 2000, if a uterine cavity was present, we used mostly a 3-mm rollerball electrode to ablate any visible endometrium and or endometrial pockets. In the absence of a recognizable uterine cavity or in the presence of narrow distorted cavities, the endometrial/endouterine cavity was resected taking small cuts with the loop electrode by alternating sides following any residual endometrial canal until the entire cavity was recreated and all visible endometrial remnants were resected (Fig. 1).

After we analyzed the results of using rollerball ablation versus loop resection for RHEA, we noticed that the rate of 


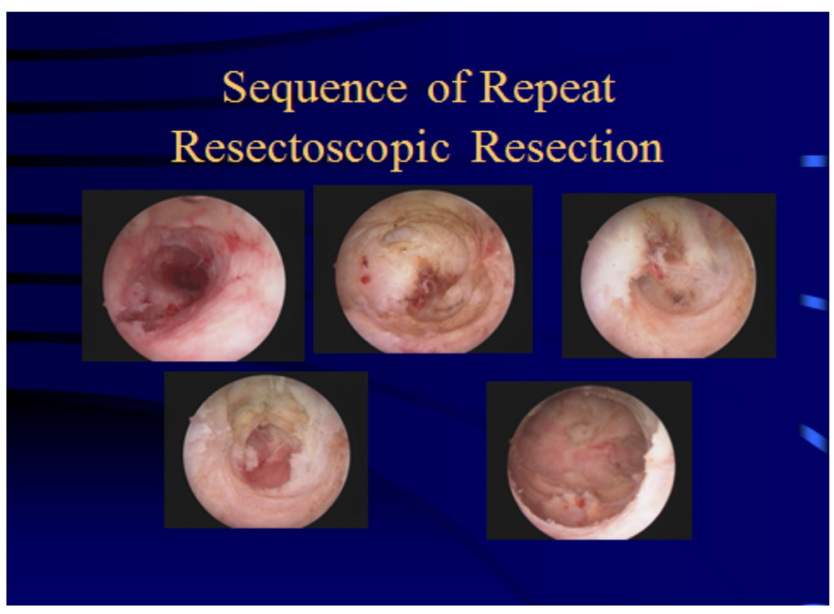

Fig. 1 Clockwise sequence of repeat hysteroscopic endometrial resection with the loop electrode

failed RHEA that underwent hysterectomy was $36.6 \%$ for rollerball compared with $23.2 \%$ for resection. In addition, we found that it was easier and safer to resect rather than rollerball the residual endometrial cavity. For this reason, around the year 2000, we started doing more RHEA using resection with the loop electrode rather than ablate with the rollerball (Fig. 2).

In the majority of RHEA, the uterus was distended using $1.5 \%$ glycine solution via an automated fluid management system (Endomat; Karl Storz GmbH \& Co., Tuttlingen, Germany) set at an infusion rate of $300 \mathrm{~mL} / \mathrm{min}$, pump pressure of $80 \mathrm{mmHg}$, and suction at 0.2 bar. Prior to the availability of this system, from the year 1990 to 2000 , a gravity system was used, at $100 \mathrm{cmH}_{2} \mathrm{O}(\sim 75 \mathrm{mmHg})$ infusion pressure with 80 $100 \mathrm{mmHg}$ wall suction, to evacuate smoke bubbles, clots, and debris from the uterus. We used a $26 \mathrm{~F}$ ( $9 \mathrm{~mm}$ diameter) monopolar resectoscope (Karl Storz GmbH \& Co., Tuttlingen, Germany) with an 8-mm monopolar loop electrode at $120 \mathrm{~W}$ of low voltage continuous (cut) waveform in 136 women $(74.3 \%)$, rollerball with high voltage interrupted (coag) waveform in 41 women $(22.4 \%)$, and a combination of the two in 6 women (3.3\%). Rollerball ablation was allowed if an endometrial cavity was reasonably well preserved. Time required to perform a RHEA is not different than that of primary HEA; approximately $15 \mathrm{~min}$.

After the university ethics board approval (HSRB 13849E), we retrospectively identified and reviewed the medical records of these women and follow-up was conducted through office visits and/or telephone interviews. Exclusion criteria included patients who did not have a minimum follow-up of 5 years since their RHEA or did not wish to participate in the study.

Data collected included patient characteristics such as age, body mass index (BMI), parity, and obstetrical history (i.e., cesarean section, vaginal deliveries) at the time of primary HEA, type of primary ablation (i.e., rollerball, resection, or both) and indications for primary and RHEA. In addition, we recorded uterine cavity findings and appearance, laparoscopic findings and procedures performed at time of RHEA for women who underwent concomitant laparoscopy, and any complications encountered during all procedures.

Follow-up data included outcome of RHEA (i.e., requirement for additional treatment such as any medical therapy, third repeat ablation, or hysterectomy), patient satisfaction, and avoidance of hysterectomy. In those women who required no further treatment after RHEA, their menstrual blood loss was classified as amenorrhea, spotting, hypomenorrhea, and persistent AUB, taking into account their age and menopausal status.

Medical records were reviewed, and telephone interviews were conducted to determine if hysterectomy was performed by a different surgeon than the surgeon who performed the RHEA. If hysterectomy was performed, efforts were made to collect data including date, indication, and histopathology of the hysterectomy specimen.
Fig. 2 Type of repeat hysteroscopic endometrial ablation versus calendar year
Type of Repeat HEA vs. Calendar Year ( $N=183)$

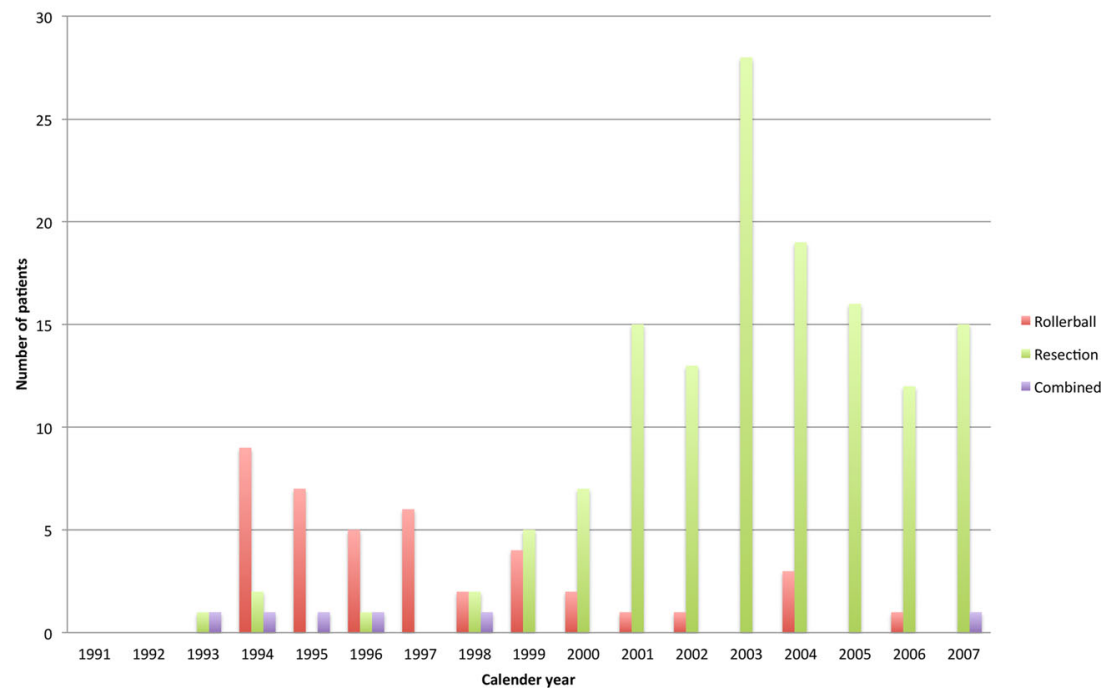


Data were analyzed using SAS software (SAS Institute, Inc., Cary, NC). The median and range are used to describe non-normal data, and the mean (SD) and $95 \%$ confidence interval are used to describe normal distribution variables. A $p$ value $<0.05$ was considered statistically significant.

\section{Results}

An algorithmic summary of the 183 women who underwent repeat HEA is provided in Fig. 3. Twenty-five (13.6\%) women were lost to follow-up. Of the remaining $158(86.3 \%)$ women with a median follow-up of 9 years (range 5-19), 102 (64.6\%) required no further treatment. Two women $(1.3 \%)$ were deceased from etiologies unrelated to RHEA, one from cervical cancer and the other from disseminated breast cancer.

The patient with cervical cancer had RHEA 6 months after HEA. Following 5 years of amenorrhea, she developed irregular vaginal bleeding and cervical biopsy indicated invasive squamous cell carcinoma, moderately differentiated (stage II b). She died of her disease 1 year after radical surgery.

The patient with breast cancer had RHEA 2 years after HEA. Ten years later, she was diagnosed with breast cancer and died of her disease 6 years after therapy.

Fifty-six women $(35.4 \%)$ required further treatment including hysterectomy $(n=49,31.0 \%)$, third HEA $(n=3$, $1.9 \%)$, or short-term medical therapy $(n=4,2.5 \%)$.

The interval from primary to repeat HEA is shown in Fig. 4 indicating that the majority $(72.1 \%)$ of RHEA were performed within the first 3 years of the primary HEA.

The demographics and characteristics of the women who received RHEA including body mass index (BMI), parity, and mode of delivery are shown in Table 1 while the indications for both are shown in Table 2. Persistent bleeding was the most common indication for both primary and RHEA.

Uterine cavity appearance and findings at RHEA The cavity appearance was described as contracted $(n=56,35.4 \%)$, containing endometrial pockets ( $n=25,15.8 \%$ ), and septum-like

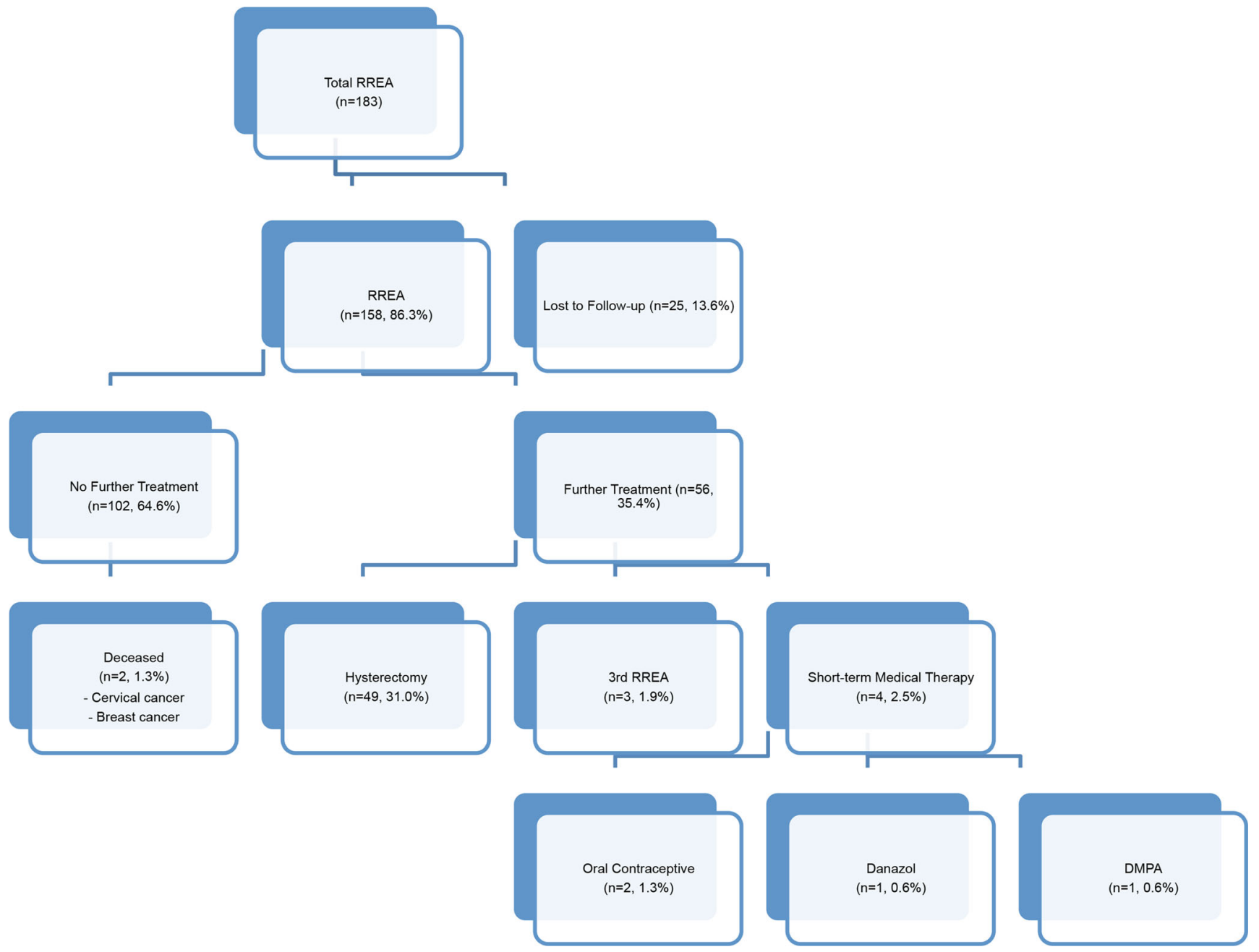

Fig. 3 Algorithmic summary of all patients who had repeat hysteroscopic endometrial ablation (HEA) 
Fig. 4 Interval in years to repeat hysteroscopic endometrial ablation

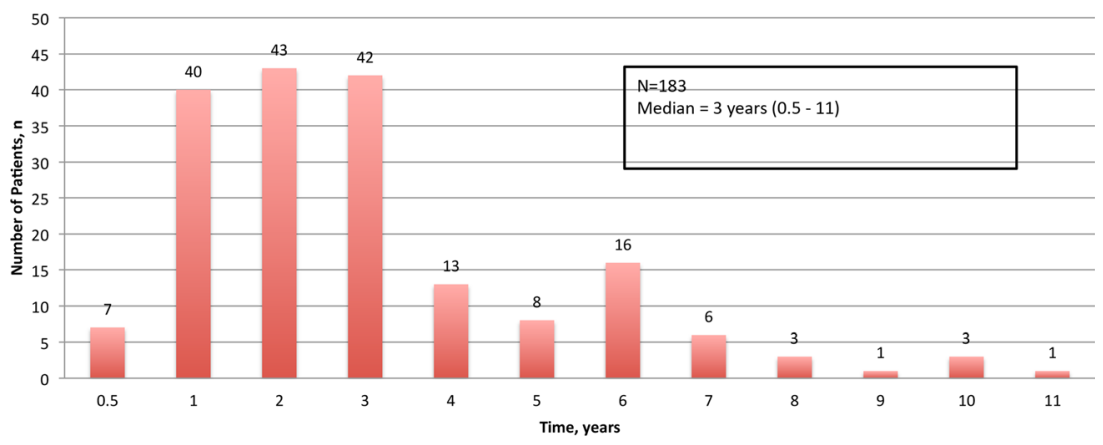

Uterine perforation with the resectoscope was encountered in two cases. One case resulted in incomplete resection and laparoscopy identified no intra-abdominal injury. This patient subsequently underwent vaginal hysterectomy for pain. Histopathology of the uterine specimen identified leiomyoma. The second case of uterine perforation did have a complete endometrial resection; however, the patient underwent abdominal hysterectomy in a peripheral hospital within a week of the RHEA for infection. There was no intra-abdominal injury noted. Histopathology of the uterine specimen was not available.

Sub-endometrial false passage was created in three cases all of which had complete resections. One patient was lost to follow-up while the other two subsequently had vaginal hysterectomy and abdominal hysterectomy for pain. Histopathology demonstrated normal tissue in the first and adenomyosis in the second case.

Two cases of RHEA resulted in excessive intraoperative bleeding. In one case, the bleeding was resolved by tamponade with a Foley catheter balloon. The second case resulted in emergency vaginal hysterectomy and adenomyosis and leiomyoma were found on histopathology.

Incomplete RHEA was performed in one patient who was morbidly obese and was lost to follow-up.

Outcomes after RHEA Of the 158 women who were followed for a minimum of 5 years, $102(64.6 \%)$ required no further treatment while 49 (31.0\%) had hysterectomy, $3(1.9 \%)$
Table 1 Demographics and type of endometrial ablation of 183 women who underwent RHEA $(\%)$

\begin{tabular}{llll}
\hline & & Primary ablation & Repeat ablation \\
\hline Age (years), median (range) & & $40(26-70)$ & $43(29-76)$ \\
Body mass index $\left(\mathrm{kg} / \mathrm{m}^{2}\right)$, median (range) & $25.1(17.7-61.2)$ & \\
Parity & Nulliparous & $19(10.4)$ & \\
& Parous & $164(89.6)$ & \\
Mode of delivery & Cesarean section & $34(18.6)$ & $41(22.4)$ \\
Type of ablation & Vaginal delivery & $130(71.0)$ & $136(74.3)$ \\
& Rollerball & $87(47.5)$ & $6(3.3)$ \\
\hline
\end{tabular}


Table 2 Indications for primary and repeat hysteroscopic endometrial ablation $(\mathrm{N}=183)$

\begin{tabular}{lll}
\hline Indication & Primary & Repeat \\
\hline AUB (1 with simple hyperplasia) & $159(86.9 \%)$ & $97(53.0 \%)$ \\
AUB + dysmenorrhea/pain & $19(10.4 \%)$ & $48(26.2 \%)$ \\
Dysmenorrhea/pain & $2(1.1 \%)$ & $35(19.1 \%)$ \\
PMB (undiagnosed) & $3(1.6 \%)$ & $2(1.1 \%)$ \\
Thickened endometrium & - & $1(0.5 \%)$ \\
Total & $183(100 \%)$ & $183(100 \%)$ \\
\hline
\end{tabular}

underwent third HEA, and 4 (2.5\%) were administered shortterm medical therapy including oral contraceptives $(n=2$, $1.3 \%$ ), danazol ( $n=1,0.6 \%$, Sanofi-Aventis Canada Inc., Laval, QC, Canada), and depo-medroxyprogesterone acetate (DMPA, $n=1,0.6 \%$ ) (Fig. 3).

Indications for hysterectomy The most common indication for hysterectomy after RHEA was pelvic pain $(n=22,44.9 \%)$ followed by pelvic pain and bleeding $(n=17,34.7 \%)$, and bleeding alone ( $n=4,8.2 \%)$. Six women $(12.2 \%)$ had hysterectomy with or without salpingo-oophorectomy for other indications including uterine prolapse $(n=1,2.0 \%)$, leiomyoma ( $n=3,6.1 \%)$, breast cancer $(n=1,2.0 \%)$, and uterine perforation and sepsis $(n=1,2.0 \%)$.

Type of hysterectomy The most common type of hysterectomy performed was vaginal $(n=24,49 \%)$, followed by total abdominal $(n=18,36.7 \%)$ and laparoscopic-assisted vaginal hysterectomy (LAVH, $n=6,12.2 \%)$. One $(2.0 \%)$ hysterectomy was not performed by the senior author (GAV), and thus, the type of hysterectomy and histopathology was unknown as hospital records were not accessible.

Histopathology of hysterectomy specimens The most common histopathology of hysterectomy specimens after RHEA was adenomyosis $(n=18,37.0 \%)$ followed by no specific pathology $(n=14,28.6 \%)$, and leiomyoma $(n=12,24.5 \%)$. Two specimens $(4.1 \%)$ included endometriosis and one specimen included simple endometrial hyperplasia without atypia $(2.0 \%)$. Four $(8.2 \%)$ histopathology results are unknown.

\section{Discussion}

Review of the available literature on long-term clinical outcomes of endometrial ablation for the treatment of AUB raises several observations, questions, and concerns.

One observation is that both HEA and non-HEA, by any technique or technology, appear to be of diminishing effectiveness with time [5-7]. As presented in the "Introduction," it is becoming more evident that within the first 10 years of endometrial ablation, up to $30 \%$ of women end up with a hysterectomy for a variety of reasons mostly related to the original problem of AUB and/or pain.

Since the median age of women undergoing endometrial ablation is in their early 40 s and $30 \%$ of them require hysterectomy within the next 10 years to resolve their original problem of AUB/dysmenorrhea, it stands to reason that at least an additional $10 \%$ of women will require hysterectomy for other indications including uterine neoplasia, pain, prolapse, etc., during their lifetime. If one accepts this reasoning with a hysterectomy rate exceeding $30 \%$ after endometrial ablation, then endometrial ablation may no longer be cost-effective [19]..

For these reasons, if one is to preserve endometrial ablation in everyday clinical practice, strategies must be developed to improve its feasibility and increase its safety and long-term efficacy.

One strategy to maintain utilization of endometrial ablation and minimize hysterectomy may be a wider utilization of repeat endometrial ablation. As stated in the "Introduction," several authors have reported their experience with RHEA after failed HEA [12-16] and non-HEA [18, 20]. However, since the literature on repeat ablations is very scanty, it is reasonable to assume that this is not a very appealing and widely practiced option. This lack of appeal may be related to a number of reasons including the lack of surgical experience and expertise, increased complications, the absence of evidence-based long-term efficacy, and the ease of solving the problem definitively with a simple hysterectomy.

As stated above, from 1991 through 1999, RHEA in our center was performed mostly by rollerball ( $67 \%)$ while from around the year 2000 to the present, RHEA is performed mostly by resection (93\%). We have found that the use of the loop electrode under direct vision is safer and more efficacious than the rollerball as shown by reduced rates of complications and hysterectomy in the present study and that of Istre and Langebrekke [14] using a similar technique to ours. On the other hand, Wortman and Daggett $[12,20]$ advocate the use of concomitant ultrasonic guidance during RHEA. This additional feature however, although conferring an element of safety, requires additional utilization of ultrasound equipment and personnel in the operating room.

We have previously reported higher complications associated with RHEA (OR 4.01, $95 \%$ CI 1.63-9.87) than primary HEA. However, those numbers may reflect lack of experience at that time and the different technique we used prior to the year 2000. In our previous study, the overall complication rate for RHEA was $9.30 \%$ ( 7 cases out of 75 ) versus $2.05 \%$ (20 cases out of 800) for RHEA ( $p=0.006)$ [16].

In the present study, the overall complication rate with RHEA was $3.8 \%$. The present complications are similar to those reported by others, with one study reporting two uterine and one cervical perforations $(4.5 \%)$. The three women with 
perforation were operated by less-experienced endoscopic surgeons [15]. The three other studies reported no complications [12-14]. This indicates that RHEA may be a relatively safe procedure when performed by experienced surgeons.

Although RHEA has been reported to be feasible and relatively safe, feasibility is not an indication unless it is shown to be effective. In our study, following RHEA, $69 \%$ of women avoided hysterectomy including 17/158 (10.8\%) women who had undergone concomitant laparoscopy This rate is within the range of 54 to $100 \%$ within 5 years of follow-up reported by others [12-15]. Whether this rate is significant enough to justify repeat ablation as an alternative to hysterectomy or bypass it all together and go directly to a vaginal or laparoscopic hysterectomy cannot be answered at this time.

In the present study, indications for repeat ablation were persistent AUB (53\%), uterine/pelvic pain (19\%), or both AUB and pain $(26 \%)$ while the most common indication for hysterectomy after RHEA was pelvic pain ( $45 \%$ ) followed by pelvic pain and bleeding (35\%). Similar results have been reported by others reporting 33 (28\%) of RHEA receiving hysterectomy for pain $(48 \%)$, persistent bleeding $(27 \%)$, and pain and bleeding (10\%) [14]. It is of interest to note that all authors report that hysterectomy was performed at a median of approximately 3 years after RHEA [12, 14, 15].

Pelvic pain after endometrial ablation has been attributed to several conditions including adenomyosis, hematometra, post-ablation tubal sterilization syndrome (PATSS), endometriosis, and others [21-23]. Indeed, in our study, the most common histopathology of hysterectomy specimens after RHEA was adenomyosis (37\%). Adenomyosis in hysterectomy specimen was reported from 58 to $61 \%$ in three other studies $[12,14,15]$.

The low rate of hematometra $(n=14,8.9 \%)$ and PATSS $(n=3)$ may be related to our technique of meticulous electrocoagulation or complete resection of the tubal cornua as described previously [24]. Sterilization by tubal occlusion has been identified as a predictor of pain after endometrial ablation $[23,25,26]$. It is thought that some of these patients experience pain caused by medial tubal accumulation of blood originating from residual cornual endometrium [23].

In our study, $79 \%$ of women reported amenorrhea, $8 \%$ spotting, and $15 \%$ hypomenorrhea. Of these, $96 \%$ were satisfied and $99 \%$ felt that it was worthwhile to have undergone RHEA. Gimpleson and Kaigh reported that RHEA resulted in amenorrhea in 10 women (63\%), staining in $3(19 \%)$, and light flow in $3(19 \%)$ [13], while Wortman and Daggett reported that $88.5 \%$ achieved satisfactory results and avoided hysterectomy [12].

We did not use any pretreatment to thin the endometrium prior to RHEA believing that identification of residual endometrium may be more difficult. In fact, Hansen et al. reported that pretreatment increased the risk of subsequent hysterectomy ( 81 vs $30 \%, p>0.01$ ) possibly due to difficulties in identifying endometrial mucosa, in these scarred and distorted uterine cavities, when pretreatment is used [15].

Additional strategies to increase efficacy of primary endometrial ablation have included better patient [27] selection and/or endometrial ablation technology [28]. However, the long-term clinical outcomes (up to 10 years) are similar among all endometrial ablation technologies [6] and no significant differences in effectiveness or safety have been found between first- and second-generation endometrial ablation techniques $[29,30]$.

A final strategy may be to combine endometrial ablation with adjunct therapy.

Indeed, preliminary studies indicate that the combination of both HEA and non-HEA with DMPA [31, 32] or the levonorgestrel intrauterine system (LNG-IUS) [33-36] significantly improve short-term clinical outcomes in women with AUB as determined by amenorrhea, satisfaction, and reintervention rates.

This study is of clinical significance since it highlights several issues including feasibility, safety, and long-term effectiveness of repeat endometrial ablation. Strengths of the study include the largest number of patients treated by both primary and RHEA and the longest follow-up reported to date while weaknesses include the retrospective nature and reflection of only one surgeon's experience.

In summary, we have shown that RHEA is a feasible, relatively safe, and a long-term effective alternative to hysterectomy for AUB from benign causes when performed by experienced surgeons. However, two observations must be pointed out regarding RHEA.

The first observation is that all authors have reported on using the resectoscope to perform repeat ablations rather than any of the nonhysteroscopic technologies. This, together with the fact that the majority of endometrial cavities after primary ablation by all methods is significantly distorted [37,38], indicates that repeat ablation may not be feasible and possibly dangerous, when attempted/performed by any technique other than the hysteroscopic approach.

The second observation is that RHEA has been reported mostly by some of the pioneers and expert surgeons on the use of resectoscopic surgery including HEA [12-16]. However, since presently, HEA has been mostly substituted by nonHEA techniques $[39,40]$, the art of HEA may be on its way to extinction. Consequently, the more technically difficult and skill-demanding RHEA will remain in the domain of a handful of surgeons and not an option provided by the majority of gynecologists.

Conflict of interest The authors declare that they have no competing interests.

Precis Repeat hysteroscopic endometrial ablation is a feasible, safe, and long-term effective alternative to hysterectomy for benign abnormal uterine bleeding when performed by experienced surgeons. 


\section{References}

1. Papadopoulos NP, Magos A (2007) First-generation endometrial ablation: roller-ball vs loop vs laser. Best Pract Res Clin Obstet Gynaecol 21:915-929

2. (2007) ACOG Practice Bulletin No. 81, May 2007: endometrial ablation. Obstet Gynecol 109(5):1233-48

3. Garry R, for the Endometrial Ablation Group (2002) Evidence and techniques in endometrial ablation: consensus. 2002. Gynecol Endosc 11(1):5-17

4. Madhu CK, Nattey J, Naeem T (2009) Second generation endometrial ablation techniques: an audit of clinical practice. Arch Gynecol Obstet 280:599-602

5. Munro MG (2006) Endometrial ablation. Where have we been? Where are we going? Clin Obstet Gynecol 49(4):736-766

6. Longinotti MK, Jacobson GF, Hung YY, Learman LA (2008) Probability of hysterectomy after endometrial ablation. Obstet Gynecol 112(6):1214-1220

7. Bhattacharya S, Middleton LJ, Tsourapas A et al (2011) Hysterectomy, endometrial ablation and Mirena ${ }^{\circledR}$ for heavy menstrual bleeding: a systematic review of clinical effectiveness and costeffectiveness analysis. Health Technol Assess 15(19):iii-xvi, 1-252

8. Wright JD, Devine P, Shah M et al (2010) Morbidity and mortality of peripartum hysterectomy. Obstet Gynecol 115:1187-1193

9. Boyd LR, Novesky AP, Curtin JP (2010) Effect of surgical volume on route of hysterectomy and short-term morbidity. Obstet Gynecol 116:909-915

10. Roberts TE, Tsourapas A, Middleton LJ et al (2011) Hysterectomy, endometrial ablation, and levonorgestrel releasing intrauterine system (Mirena) for treatment of heavy menstrual bleeding: cost effectiveness analysis. BMJ 342:d2202. doi:10.1136/bmj.d2202

11. Clark-Pearson DL, Geller EL (2013) Complications of hysterectomy. Clin Exp Ser Obstet Gynecol 121:654-673

12. Wortman M, Daggett A (2001) Reoperative hysteroscopic surgery in the management of patients who fail endometrial ablation and resection. J Am Assoc Gynecol Laparosc 8(2):272-277

13. Gimpelson RJ, Kaigh J (1992) Endometrial ablation repeat procedures. Case studies. J Reprod Med 37(7):629-635

14. Istre O, Langebrekke A (2003) Repeat hysteroscopic surgery reduces the hysterectomy rate after endometrial and myoma resection. J Am Assoc Gynecol Laparosc 10(2):247-251

15. Hansen BB, Dreisler E, Stampe SS (2008) Outcome of repeated hysteroscopic resection of the endometrium. J Minim Invasive Gynecol 15(6):704-706

16. MacLean-Fraser E, Penava D, Vilos GA (2002) Perioperative complication rates of primary and repeat hysteroscopic endometrial ablations. J Am Assoc Gynecol Laparosc 9(2):175-177

17. Yeung GW, Vilos GA, Garcia-Erdeljan M, Marks JL, Vilos AG, Abu-Rafea B (2012) Repeat resectoscopic endometrial resection after failed primary resectoscopic endometrial ablation: Is it worth the risk? J Minim Invasive Gynecol 19(6):S22

18. Garcia-Erdeljan M, Vilos GA (2012) Repeat hysteroscopic endometrial resection after failed thermal balloon endometrial ablation: is it worth the risk? J Minim Invasive Gynecol 17:S25

19. Laberge P, Leyland N, Murji A, Fortin C, Martyn P, Vilos GA (2015) Endometrial ablation in the management of abnormal uterine bleeding. J Obstet Gynaecol Can 37(4):362-376

20. Wortman M (2013) Sonographically guided reoperative hysteroscopy (SGRH) for the management of global endometrial ablation (GEA) failures: a review of 50 cases. J Minim Invasive Gynecol 20:S53

21. Thomassee MS, Curlin H, Yunker A, Anderson TL (2013) Predicting pelvic pain after endometrial ablation: which preoperative patient characteristics are associated? J Minim Invasive Gynecol 20:642-647
22. Sharp TH (2012) Endometrial ablation: postoperative complications. Am J Obstet Gynecol 207(4):243-247

23. McCausland AM, McCausland VM (2010) Long-term complications of minimally invasive endometrial ablation devices. J Gynecol Surg 26(2):133-149. doi:10.1089/gyn.2009.0016

24. Vilos GA, Oraif A, Vilos AG, Ettler E, Edris F, Abu-Rafea B (2015) Long-term clinical outcomes following resectoscopic endometrial ablation of non-atypical endometrial hyperplasia in women with abnormal uterine bleeding. J Minim Invasive Gynecol 22:66-77. doi:10.1016/j.jmig.2014.07.009

25. El-Nashar SA, Hopkins MR, Creedon DJ, St Sauver JL, Weaver AL, McGree ME et al (2009) Prediction of treatment outcomes after global endometrial ablation. Obstet Gynecol 113:97-106

26. Peeters JA, Penninx JP, Mol BW, Bongers MY (2013) Prognostic factors for the success of endometrial ablation in the treatment of menorrhagia with special reference to previous cesarean section. Eur J Obstet Gynecol Reprod Biol 167:100-103

27. Wishall KM, Price J, Pereira N, Butts SM, Della Badia CR (2014) Postablation risk factors for pain and subsequent hysterectomy. Obstet Gynecol 124:904-910. doi:10.1097/AOG.0000000000000459

28. Daniels JP, Middleton LJ, Champaneria R, Khan KS, Cooper K, Mol BW et al (2012) Second generation endometrial ablation techniques for heavy menstrual bleeding: network metaanalysis. BMJ 344:e2564

29. Lethaby A, Hickey M, Garry R (2005) Endometrial destruction techniques for heavy menstrual bleeding. Cochrane Database Syst Rev 4. Wiley. [DOI: 10.1002/14651858]

30. Fernandez H (2011) Update on the management of menometrorrhagia: new surgical approaches. Gynaecol Endocrinol 1:1131-1136

31. Townsend DE, Richart RM, Paskowitz RA, Woolfork RE (1990) "Rollerball" coagulation of the endometrium. Am J Obstet Gynecol 76:310-313

32. Goldrath MH (1995) Hysteroscopic endometrial ablation. Obstet Gynecol Clin NA 22:559-572

33. Al-Shukri M, Burnett M (2009) Combined intervention with endometrial ablation plus LGN-IUS versus ablation alone for the treatment of menorrhagia. J Obstet Gynecol Can 31(5):S25

34. El-Nashar SA (2010) Combined bipolar radiofrequency endometrial ablation with levonorgestrel intrauterine system: a novel approach for challenging cases. J Minim Invasive Gynecol 17:S37

35. Vaughan D, Byrne P (2012) An evaluation of the simultaneous use of the levonorgestrel-releasing intrauterine device (LNG-IUS, Mirena ${ }^{\circledR}$ ) combined with endometrial ablation in the management of menorrhagia. J Obstet Gynaecol 32:372-374. doi:10.3109/ 01443615.2012 .666581

36. Sohn B, Vilos GA, Vilos AG, Ternamian A, Abu-Rafea B, Oraif A (2013) Resectoscopic rollerball endometrial ablation and concomitant levonorgestrel-releasing intrauterine system in women with abnormal uterine bleeding: is the combination better? J Minim Invasive Gynecol 20:S22

37. Magos AM, Baumann R, Lockwood GM, Turnbull AC (1991) Experience with the first 250 endometrial resections for menorrhagia. Lancet 337:1074-1080

38. Taskin O, Onoglu A, Inal M et al (2002) Long-term histopathologic and morphologic changes after thermal endometrial ablation. J Am Assoc Gynecol Laparosc 9(2):186-190

39. Reid PC (2007) Endometrial ablation in England - coming of age? An examination of hospital episode statistics 1989/1990 to 2004/2005. Eur J Obstet Gynecol Reprod Biol 135:191-194

40. Fergusson RJ, Lethaby A, Shepperd S, Farquhar C (2013) Endometrial resection and ablation versus hysterectomy for heavy menstrual bleeding. Cochrane Database Syst Rev 11. Art. No.: CD000329. DOI:10.1002/14651858.CD000329.pub2 